\title{
Reconstructive surgery for thumb osteomyelitis: a new way of remodelling the vascularized medial femoral condyle flap. A case report.
} Rekonstruktive Operation bei Osteomyelitis des Daumens -
eine neue Möglichkeit zur Remodellierung der vaskularisierten
Lappenplastik aus dem medialen Femurkondylus. Ein Fallbericht.

Autoren

Carlo Rossello ${ }^{1}$, Andrea Antonini ${ }^{2}$, Andrea Zoccolan¹, Giorgio Burastero ${ }^{2}$, Mario Igor Rossello ${ }^{1}$

Institute

1 Ospedale San Paolo Hand Surgery

2 ASL2 Savonese Malattie Infettive e Ortopedia Settica

Schlüsselwörter

Osteomyelitis, Rekonstruktion, Lappenplastik aus dem medialen Femurkondylus, Daumen

Key words

Osteomyelitis, reconstruction, medial femoral condyle flap, thumb

eingereicht 31.01 .2019

akzeptiert $\quad 13.05 .2019$

Bibliografie

DOI https://doi.org/10.1055/a-0942-9652

Handchir Mikrochir Plast Chir 2019; 51: 440-443

(c) Georg Thieme Verlag KG Stuttgart · New York

ISSN 0722-1819

Korrespondenzadresse

Dr. Carlo Rossello

Ospedale San Paolo Hand Surgery

Via Genova 30

17100 Savona

Tel.: 0198404367

Fax: 0198404984

E-Mail: carlorossellomd@gmail.com

\section{ZUSAMMENFASSUNG}

Hintergrund Die Autoren präsentieren eine technische Innovation zur Remodellierung der Lappenplastik aus dem Condylus medialis femoris (MFCF) zur Rekonstruktion kleiner bis mittelgroßer Knochendefekte nach operativer Behandlung der Osteomyelitis des Daumens.

Material und Methoden Ein 45-jähriger Patient mit Osteomyelitis der proximalen Daumenphalanx infolge einer Quetschverletzung der dominanten rechten Hand stellte sich nach mehreren erfolglosen Operationen in anderen Krankenhäusern bei uns vor. In unserer Klinik unterzog er sich einer zweistufigen chirurgischen Behandlung der Infektion durch Knochen- und Weichteilrekonstruktion mit einer Lappenplastik aus dem medialen Femurkondylus, die unter Anwendung eines neuen dreidimensionalen (3D) Verfahrens mit mehreren Osteotomien modelliert wurde.

Ergebnisse Nach 30 Tagen wurde eine knöcherne Durchbauung mit stabiler Rekonstruktion des Daumens und guter Abheilung der Weichteile erreicht. Nach dem Eingriff traten keine vaskulären Komplikationen auf. Es fanden sich keine Hinweise auf ein Infektionsrezidiv.

Schlussfolgerungen Es gibt eine Vielzahl an Möglichkeiten für die 3D-Formgebung der Lappenplastik aus dem medialen Femurkondylus. Daher stellt diese bei handchirurgischen Rekonstruktionen nach chirurgischer Exzision kleiner und mittelgroßer Knochensegmente eine gute Lösung dar.

\section{ABSTRACT}

Background Authors propose a technical innovation for the remodelling of the medial femoral condyle flap (MFCF) for reconstruction of small to medium bone defects performed after the surgical treatment of a thumb osteomyelitis.

Materials and Methods A 45 year old male had thumb proximal phalanx osteomyelitis after a crush trauma of the dominant right hand and multiple previous unsuccessful surgical attempts in other hospitals. In our centre he underwent to a two stage surgical treatment of the infection through bone and soft tissue reconstruction with a MFCF shaped in a new three dimensional (3D) approach with multiple osteotomies. Results Bone union was achieved after 30 days with a stable thumb reconstruction and good soft tissue healing. No vascular complication occurred after surgery. There was no sign of infection recurrence.

Conclusions MFCF offers a variety of options for its $3 \mathrm{D}$ shaping which make it a good solution in hand surgery reconstructions after surgical excision of small and medium size bony segments. 


\section{Introduction}

Authors propose a new way of shaping the medial femoral condyle flap (MFCF) to reconstruct the hand's long bones after surgical management of a Cierny-Mader IV proximal phalanx osteomyelitis. Other authors already described the MFCF for thumb reconstructions with a single segment of revascularized corticoperiosteal bone or in association with non-vascularized cortical bone grafts [1-2]. The authors hereby report a technical development in $3 \mathrm{D}$ flap shaping to increase the use of this very ductile flap in hand surgery.

\section{Material and methods}

A 45 years old male had a 5-year long history of unsuccessful treatments after a crush injury at right hand with an exposed thumb P1 fracture. He underwent multiple surgeries in other hospitals and healing was regularly compromised by septic nonunions. When the patient came to our attention had an unstable thumb, with a fistula on the first phalanx dorsum and weak pinch strength. Radiograms showed first phalanx bone loss with presence of comminute bone substitutes and compromised distal and proximal interphalangeal joints ( $\triangleright$ Fig. 1) which made the thumb unstable and useless. The patient asked for a reliable and stable reconstructive solution in order to be able to hold at least a pencil.

Surgical approach to local osteomyelitis was performed in two stages, after an antibiotic wash-out period of over 2 weeks. During the first operation, surgeons removed infected bone and all allogenic materials used in previous surgeries through a longitudinal incision performed along dorsal aspect of the first phalanx including the cutaneous fistula. Surgical specimens were sent for bacteriological and histological examination. All infected materials and tissues were removed until macroscopic signs of infection were absent. A custom antibiotic cement spacer was inserted to help local treatment of infection and to hold the place for the bony reconstruction. Skin closure was possible with direct suture. After surgery, specific antibiotic therapy was administrated on the basis of microbiological isolations.

Three months later, the surgeons worked in two teams. One team removed the spacer through the previous dorsal surgical access and debrided the surrounding soft tissues. The residual bone gap was 24 millimetres in length. After debridement, they isolated the dorsal branch of radial artery at the wrist and a branch of the cephalic vein. The other team meanwhile harvested the medial condyle flap from the ipsilateral femur. Surgeons used a handmade $3 \mathrm{D}$ model in sterile plastic material at the recipient site to obtain the correct measure and form of the flap. On the medial condyle a $2.5 \mathrm{~cm} \times 3 \mathrm{~cm}$ side quadrangular flap was designed on the periostium, centred on visible periosteal vessels. With an osteotome the periosteum and cortical bone were harvested following the drawn lines. In the central area and along the major axis of the flap the cortical bone was elevated with sub cortical bone. Surgeons modelled the flap while still attached at the donor site maintaining vascular connections. The surgeons performed two longitudinal cortical and sub periosteal osteotomies, dividing the flap in three cortical palettes, each measuring $2.5 \mathrm{~cm} \times 1 \mathrm{~cm}$. The central palette maintained the attached subcortical cancellous bone which was accurately shaped as a triangular section prism. From lateral cortical

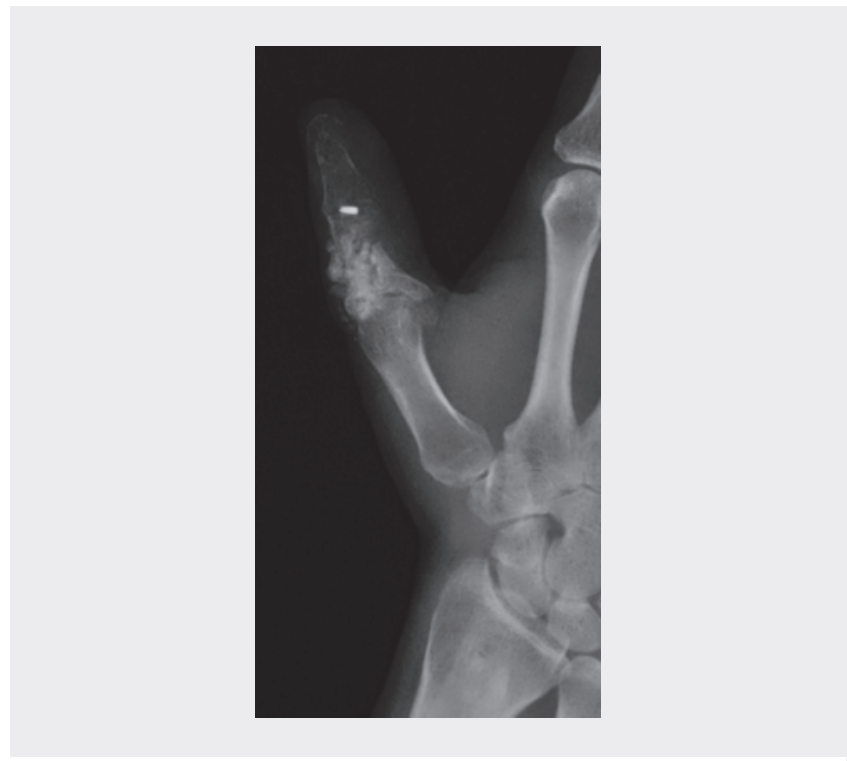

- Fig. 1 Preoperative radiograph showing septic thumb pseudoarthrosis with presence of infected bone substitute and residual internal fixation device.

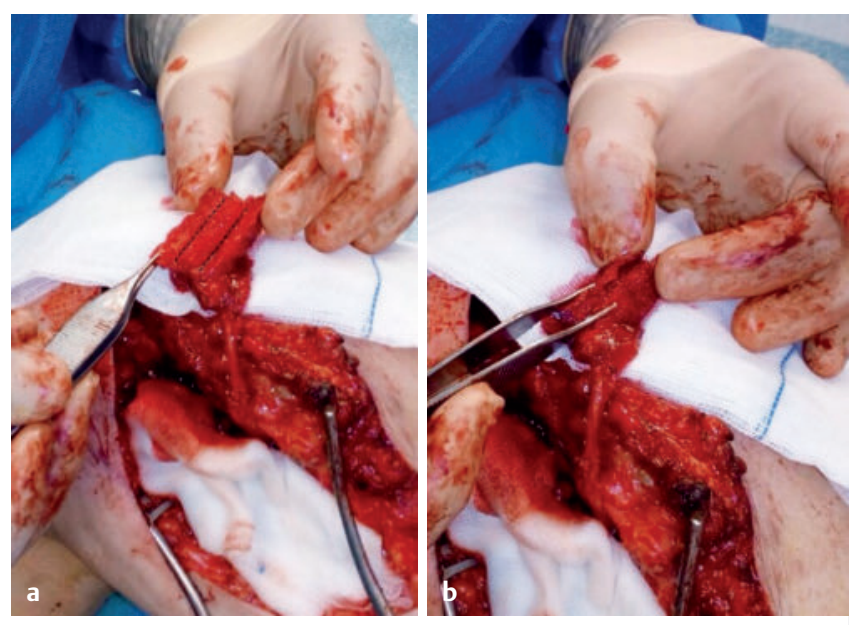

- Fig. 2 a Two longitudinal cortical and subperiosteal osteotomies dividing the flap in three cortical parts along the major axis (black dotted lines), central portion of cortical bone with attached subcortical bone and lateral cortical parts folded after osteotomies; b lateral sides close the central subcortical bone obtaining a triangular prism.

palettes, all cancellous bone was removed. The three parts maintained anatomical and vascular connections through periosteum and a thin pliable layer of cortical bone. The lateral parts of the flap were folded upon the central one along the major axis obtaining a perfect triangular prism ( $\triangleright$ Fig. 2). Periosteal sutures were performed to close the prism. A single $1.6 \mathrm{~mm}$ Kirschner $(\mathrm{K})$ wire was longitudinally introduced in the cancellous component of the flap at the donor site ( $>$ Fig. 3). The flap was then transferred to the recipient site and the insetting performed with the K-wire in an inout out-in technique into the thumb ( $\triangleright$ Fig.4). A first metacarpal - medial femoral condyle - second phalanx fusion was carried out in a good functional position. The pedicle was tunneled in the sub- 


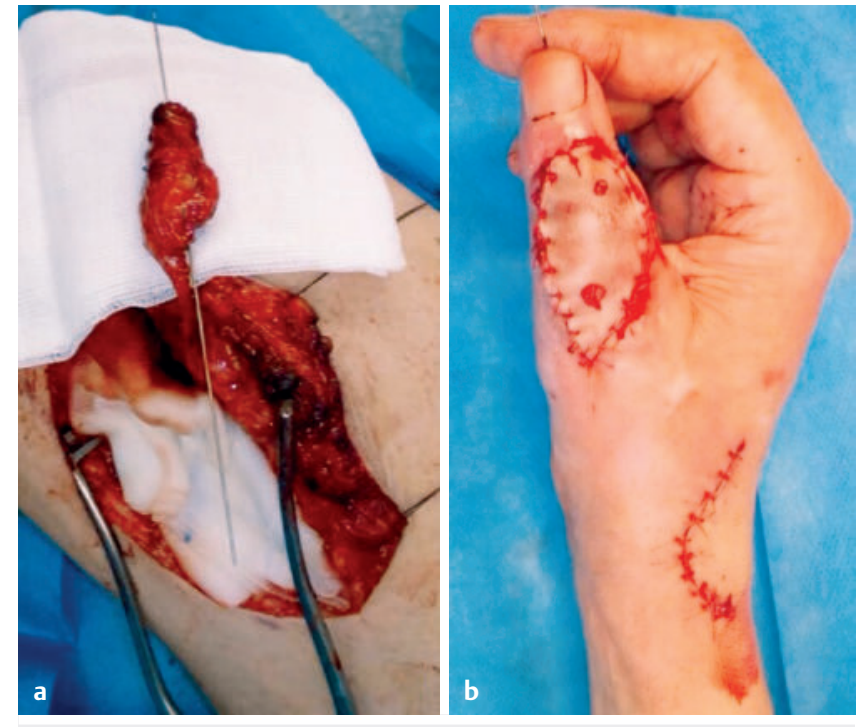

- Fig. 3 a Flap at donor site after remodelling with inserted one $\mathrm{K}$ wire; $\mathbf{b}$ thumb after insetting with skin graft on dorsal aspect.

- Fig. 4 Immediately postoperative radiograph showing insetting with one $\mathrm{k}$ wire.

cutaneous plane to reach the proximal recipient harvested vessels. The new phalanx was revascularized with end to side arterial anastomosis to the dorsal branch of radial artery and end to end venous anastomosis to a superficial tributary branch of the cephalic vein. At the donor site surgical incision a full thickness skin graft was obtained, and used for a tension free closure covering soft and perivascular tissues on the dorsal proximal aspect of the "neophalanx".

\section{Results}

No microvascular complications occurred after surgery. Radiographic bone union was achieved after 30 days, and the K-wire was removed. Radiographs were taken at 1-2-6-12-24 months ( Fig.5). No signs of infection recurrence were reported during a 32-month follow-up ( $\triangleright$ Fig. 6). The patient underwent 3 months of hand kinesiologic therapy. At the end of rehabilitation Kapandji was 9 on the operated right hand (left hand, 10). Right hand

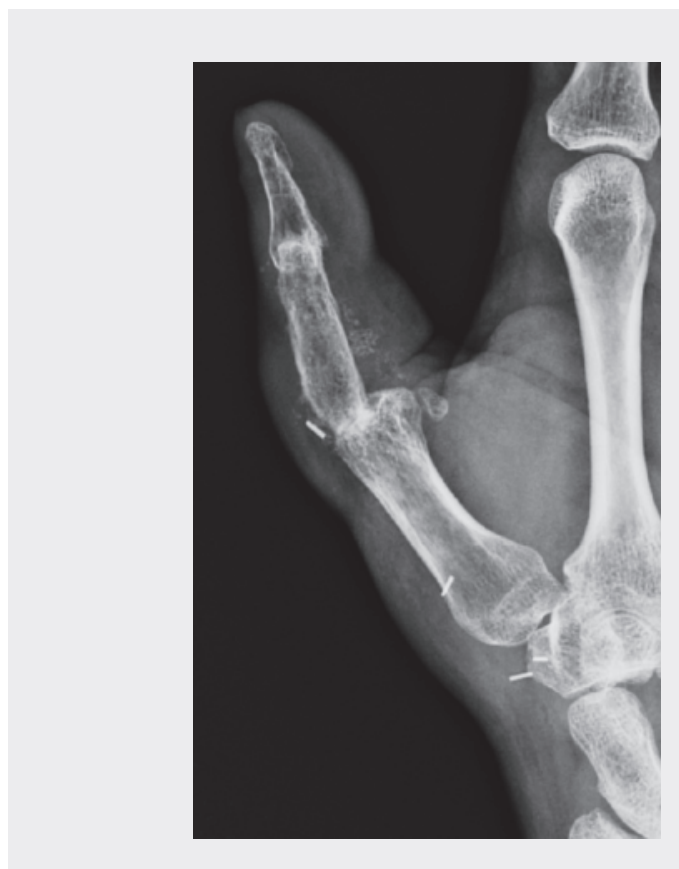

- Fig. 5 Postoperative radiograph at 18 months showing proximal and distal flap bone union.

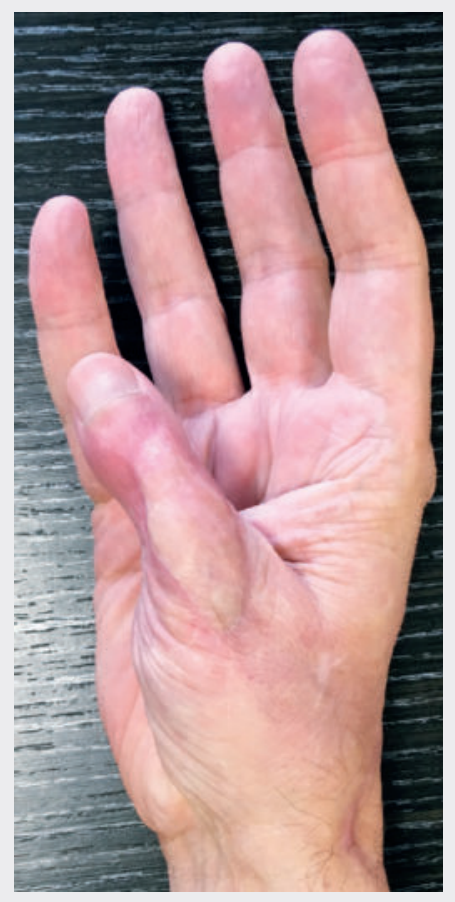

- Fig. 6 Clinical postoperative at 24 months.

grip strength was $28 \mathrm{~kg}$. Biometric pinch strength was $0.83 \mathrm{~kg}$ (left $3.66 \mathrm{~kg}$ ). Disabilities of the Arm, Shoulder and Hand score improved from 74.13 to 41.37 after surgery. No complications at donor site with full painless range of motion after 3 months. Minimal scar hypertrophy at the donor site without alteration of sensitivity. 


\section{Discussion}

Osteomyelitis requires a multidisciplinary approach, requiring antibiotic therapy, surgical management by oncologic resection of infected bone and neighbouring soft tissues, and surgical reconstruction when feasible. Vascularized bone and soft tissue reconstructions are particularly indicated in case of osteomyelitis because they have both functional and therapeutic roles, being the transferred vital tissue well perfused and therefore carrying immune cells and molecules and antibiotics into the infection site. The authors demonstrated the feasibility of multiple subperiosteal cortical osteotomies to shaping the MFCF into a completely vascularized 3D prism, useful for small and medium-size long bone defects bone defects. The crucial point is to maintain periosteal integrity during osteotomies, with a blunt and careful management of the flap. The periosteal vascular plexus is the key point of the flap. Literature reported MFCF use with many indications in hand surgery and other districts [3-5]. In hand surgery other local flaps are used for limited bone defects' reconstruction [6]. MFCF is a good solution in the treatment of bone gap in the hand after osteomyelitis because of the amount of bone tissue available. Previous authors reported the use of MFCF associated with non-vascularized bone grafts [2]. The idea of the authors was to find a new way in $3 \mathrm{D}$ shaping of this flap, avoiding the use of any non-vascularized bone tissue as advised in literature for the correct surgical management of osteomyelitis [7-8]. This particular triangular prism shape demonstrated the possibility of a good handling during the insetting operations and a good long-term stability of the skeletal reconstruction. The triangular basis of the flap was partially inserted in the base of the second phalanx and in first metacarpal bone head helping to maintain a control of rotation of the new phalanx and allowing fingertip stabilization one single $\mathrm{K}$ wire, reducing the need further hardware. The utilization of a skin graft on the vital soft tissue component of the flap over the dorsal aspect of the new phalanx did not increase the risk of infection [9].

\section{Conclusion}

Vascularized MFCF is a promising solution to reconstruct small and medium-size bone defects after resection in the treatment of osteomyelitis in hand surgery. The high potential of this flap consists in the high remodelling ductility of the periosteal tissue which maintains vascularization of all the flap components.

\section{Conflict of interest}

The authors declare that they have no conflict of interest

\section{References}

[1] Wong VW, Higgins JP, Katz RD. Functional reconstruction of subtotal thumb metacarpal defect with a vascularized medial femoral condyle flap: case report. J Hand Surg Am 2014; 39: 2005-2008
[2] Ruston JC, Amin K, Darhouse N et al. The Vascularized Medial Femoral Corticoperiosteal Flap for Thumb Reconstruction. Plast Reconstr Surg Glob Open 2015; 3: e492

[3] Malizos KN, Dailiana ZH, Innocenti et al. Vascularized bone grafts for upper limb reconstruction: defects at the distal radius, wrist, and hand. J Hand Surg Am 2010; 35: 1710-1718

[4] Henry M. Vascularized Medial Femoral Condyle Bone Graft for Resistant Nonunion of the Distal Radius. J Hand Surg Asian Pac Vol 2017; 22: $23-28$

[5] Fuchs B, Steinmann SP, Bishop AT. Free vascularized corticoperiosteal bone graft for the treatment of persistent nonunion of the clavicle. J Shoulder Elbow Surg 2005; 14: 264-268

[6] Yajima H, Tamai S, Yamauchi T et al. Osteocutaneous radial forearm flap for hand reconstruction. J Hand Surg Am 1999; 24: 594-603

[7] Lew DP, Waldvogel FA. Osteomyelitis. Lancet 2004; 364: 369-379. Review

[8] Cierny G 3 rd. Surgical treatment of osteomyelitis. Plast Reconstr Surg 2011; 127: 190-204

[9] Giessler GA, Schmidt AB. Thumb salvage with skin grafted medial femoral corticoperiosteal free flap. J Plast Reconstr Aesthet Surg 2011, 64: 1693-1696 